\title{
Digital Literacy in a Grade 8 Classroom: An E-zine WebQuest
}

by

Mary Clare Courtland

Lakehead University

Thunder Bay, Ontario, Canada

and

Dave Paddington

Lakehead Public Schools

Thunder Bay, Ontario, Canada

Subject: Do you like this project?

Kilex: Hey guys it's Kilex Gannon I wanted to now if u guys are liken this as much as I am K? Plzzz Reply (\#278)

Shane: $\quad$ Its like the cats pajamas, The beez knees it is awesome (\#308)

Joe: $\quad$ this is really cool because you can post ur ideas and you don't have to pretend to listen you don't like wat there talking about if you don't like it (real life) you can just skip it (\#311)

Sputnik: maybe we should not be having this much fun..... Its school you know.... Im going to make a journal (\#318)

Summer: $\quad$ yeah for sure this project is AWSOME..i am soo gald like everyone is all in it and I cant waite till we make our own ezine... this is awesome :) (\#344)

(Blog, Week \#1, E-zine Project)

The blog entries above were written by a group of students in a Grade 8 class who participated in a WebQuest (www.webquest.org) on teen e-zines. The WebQuest was the context for a study which explored the ways in which digital literacy mediated young adolescents' literacy learning. There were 18 students, 13 boys and 5 girls, in the class. The design of the study was qualitative and emergent (Bogdan \& Biklin, 2003; Patton, 2002). Data were collected through participant and nonparticipant observations, informal interviews and analysis of documents such as a blog, journal entries and Canteen, the teen e-zine created by the students. Data analysis was constant-comparative (Bogdan \& Bikliln, 2003). All student names are pseudonyms. Sample blog entries are unpolished first drafts. 
The study took place over a 14-day period in which the students worked in the computer lab for 75 minutes a day. By then, most groups had completed their sections of the teen e-zine. Following this time period, two members of the design team created the web page, uploaded the sections and inserted the links to connect the web pages.

\section{Conceptual Framework}

Digital literacy is a relatively recent "newcomer" to the vast array of sign systems through which human being comprehend and construct meanings. It is, perhaps, this set of interrelated sign systems which has catapulted literacy researchers and educators into redefining the boundaries of literacy. However, researchers such as Eisner (2002), Leland and Harste (1994), Marshall (2000) and Smagorinsky (2002) have long recognized the significance of representation through multiple sign systems. Leland and Harste (1994) explain: "A good language arts program is one that expands the communication potential of all learners through the orchestration and use of multiple ways of knowing for purposes of ongoing interpretation and inquiry into the world" (p. 339). They note that "the movement between and among sign systems is known as transmediation. Transmediation occurs when meanings formed in one communication system are recast in the context and expression planes of a new sign system..." (p. 340). Transmediation, then, provides learners "with new perspectives on their knowing and, hence, for the expression of an expanded range of meanings" (Leland \& Harste, 1994, p. 340).

Eisner (2002) notes that the act of representation "provides the occasions for the invention or discovery of ideas, images, or feelings that were not necessarily present at the inception of the activity" (p. 80). He suggests that we are still coming to understand "the unique epistemological functions that different expressive forms make possible" (p. 148).

In order for students to express and/or represent their meanings in a medium, they must learn the techniques and tools of the medium (Goldberg, 2001; Marshall, 2000). In two studies which investigated the ways in which young adolescents' comprehension and 
response were mediated by different sign systems, Courtland and her colleagues (Courtland et al., 2006; Courtland et al., forthcoming) found that introducing students to the conventions of the medium enabled them to represent their ideas creatively and imaginatively. The acts of representation in drama (Courtland et al., forthcoming) and acrylic painting (Courtland et. al., 2006) involved composing, a process similar to the writing process in that representation was recursive and included the generation of ideas, drafting, revising and completing a "polished" work.

Kist (2005) locates new literacies or multiliteracies within the context of multiple sign systems:

...I am holding to a concept of new literacies that is not wholly dependent on technology - that is, as Eisner states, even such "old fashioned" forms as dance and drama can be "read" and "written." In short, there should be no form of representation that is not embraced or is out of favor in this world that is becoming dominated by textually mediated worlds such as games and chat rooms that are more transitory in nature. (pp. 12-13)

Eagleton (2002), whose work informed the analysis of data in this study, has mapped the genres, sign systems and cueing systems of print literacy alongside those involved in hypermedia literacy. She suggests that hypermedia literacy "requires the ability to orchestrate and transmediate among oral, print, visual, computer, and hypertext literacies" (p. 1). In her study of hypermedia composition in a Grade 7 class where students created an e-zine, Eagleton found that students needed to have fluency in reading and writing skills to accomplish their tasks. Similarly, they used oral language to communicate with teacher and peers. Visual literacy involved "designing and viewing still images" (p. 6) and familiarity with elements such as colour and layout. Eagleton explains that computer literacy "has come to mean possessing the ability to navigate an operating system, use software applications, produce digital projects, and solve small technical problems" (p. 6). She found that the students had no difficulty navigating the web (hypertext literacy) and that the cueing systems involved in hypertext literacy necessitated students' learning and using text, graphics, photography, and icons. She notes that "hypermedia authors must 
have some familiarity with each [convention] in order to be considered literate in this medium" (p. 10).

A number of authors such as Kist (2005) and Pahl and Rowsell (2005) have argued that educators must bring students' out-of-school literacies into their in-school literacy programs and that "context, identity and practice are three key terms central to any reading and writing event - in school or out of school" (Pahl \& Rowsell, 2005, p. 3). Pahl and Rowsell (2005) note that all literacy events are embedded in sociocultural contexts. They draw on individuals' cultural experiences and social practices. They explain that identity is an integral dimension of literacy learning:

The way we express our identity is partly through language. We also express our identity through our dress, artefacts we have around us, our way of talking, being and gesturing and in our homes, communities and families. We create our identity through social practices... Literacy practices are infused with identity. (p. 98)

Leu Jr., Kinzer, Coiro, and Cammack (2004) contend that many students come to school with more knowledge about some of the new literacies than most adults. They describe the phenomenon of "social learning" (p. 21) which builds upon the idea that learning is socially constructed: "Young students possess higher levels of knowledge about some of these new literacies than most adults. It is simply impossible for one person to know all the new literacies and teach these directly to others. Each of us, however, will know something unique and useful to others" (p. 21). The authors note that one implication for the changing role of the teacher is the shift from being the sole authority to orchestrating "complex contexts for literacy and learning" (p. 22) in which students who have expertise are encouraged to share with others in the classroom.

The study was embedded in a social constructivist, reader response framework (Courtland \& Gambell, 2000) and views print literacy and multiliteracies as sign systems through which human beings construct and express meanings. Representation involves reinterpretation and composing. Familiarity with the conventions of a medium enables 
students to express and represent their ideas (Eagleton, 2002; Goldberg, 2001; Marshall, 2000).

The study and WebQuest were based on Eisner's (2002) conception of curriculum as "cognitive pluralism" (pp. 79-83) which includes plurality of knowledge (the range of sign systems through which human beings represent ideas) and plurality of intelligences (Gardner, 1983, cited in Eisner, 2002). The WebQuest incorporated Eisner's dimensions of curriculum planning: goals, content, types of learning opportunities, organization of learning opportunities, organization of content areas, mode of presentation and mode of response (pp. 133-153).

The following sections describe the WebQuest and organization of the unit, themes which emerged from the analysis of data, and discussion.

\section{Teen E-zines: A Media WebQuest}

A WebQuest (www.webquest.org) was selected as the approach for the e-zine project because it allowed the teachers to select age- and content-appropriate teen e-zines in advance for students to read. This introduction to e-zines was intended to provide scaffolding to students so that they would become familiar with the content and genre of a variety of teen e-zines. The WebQuest explained to students that their school magazine was not as popular as it had been and that the editor-in-chief was looking for a new format to increase circulation. In the role of reporters, students were asked to read and critique teen e-zines and then to create a model e-zine.

The WebQuest featured the following sections: Introduction, Task, Process, Resources (links to 12 teen e-zines), Expectations, Report, Evaluation Rubrics, and Grading (http://flash.lakeheadu.ca/ webquest/). The WebQuest was mounted on the WebCT platform and included a public blog and a private journal. The blog was intended to be asynchronous; however, because students were logged on to the computers at the same 
time each day, it quickly became a chat room. Most of the students chose to paste their journal entries into the blog.

Students were assigned to response groups of three. Following the reading and analysis of e-zines, each of the six groups selected a theme and collaborated to develop a section of the e-zine. A design team, one representative per group, then worked together to design the central page and create the icons to link the sections.

Initially, the classroom teacher posted the names of group members on the blog as well as instructions for the tasks he wanted them to accomplish that day. He used the large screen in the computer lab to illustrate how students would log onto WebCT. He instructed them to browse the WebQuest and some of the e-zines. When they began the WebQuest, none of the students were familiar with e-zines. Each day, the teacher would begin the period by asking the class to turn off their screens. He would then discuss the expectations for the day. The class engaged daily in whole class discussions, computer time, and planning meetings with their response groups. Thus, oral language was used regularly for communication.

The teacher monitored students' postings and their progress daily. He was online in class and was quick to correct the first inappropriate "putdown" posted on the blog. This behaviour did not occur again. He was also concerned about "trivial" exchanges on the blog and developed guidelines for blog entries. Students, however, were so exuberant that they quickly forgot his admonitions and lapsed into chat frequently. However, they were also completing the required tasks. The teacher encouraged students to resubmit the critiques of the e-zine sections and to develop proposals for their own e-zine in greater depth. Both the teacher and the university researcher responded regularly to journal entries.

In week \#1, students read and critiqued the e-zines. The groups also began to develop the proposals for their sections. In week \#2, they revised their proposals, had them approved by the teachers and started the research for their sections. In week \#3, they continued their research and began to compose their sections. The time allotted for the Language and Literacy

Volume 10 Issue 1 Spring 2008 
project ended in week \#3. By then, most of the individual sections had been completed. Two members of the design team worked on the web page while the class continued with the regular curriculum.

\section{Themes}

Two themes are presented below. The first, The Great Outdoors, describes the individual and response group processes involved in exploring and reviewing teen e-zines as well as the development of this section of the e-zine. The second theme describes the creation of the e-zine, Canteen: A Site for Canadian Teens, and focuses on the role of the design team, successes and challenges experienced by teachers and students in the production of Canteen, and lastly, post-data collection reconstruction of the website.

\section{The Great Outdoors}

Exploring e-zines. On the first day of the unit, the teacher encouraged students to browse the e-zines posted on the WebQuest and then meet in response groups to discuss which ones each member would review. Several students asked for clarification of the terms "target audience" and "special effects."

Gerame Stevenson, Ariel Ana Dew and Maddy Black [pseudonyms] were members of one response group. Gerame was a skilled computer user. Although his first journal entry did not describe his "techie" skills, his reviews of e-zines demonstrated fluency in computer literacy, visual literacy, and awareness of hypermedia. For example, in his review of Equality Today, he wrote, "I liked how the Web site was designed. The background, flashy colours and useful links provided me with a fairly good web site experience."

Most individuals in the class initially wrote brief reviews. The teacher, who monitored postings continually, asked students to provide greater detail and to give their opinions on the section of the e-zine they reviewed. He invited them to revise and resubmit. He posted the following feedback to Gerame in the private area: 
Nice to see you did three. I would take the time to review what a review is... hahaha. Think of a movie review, book review or gaming review. The author details the ups and downs and ins and outs of the topic peppering the article with their opinions. Take the time to do this. Remember it is quality not quantity. I liked your ratings but the use full sentences, examples from the sites and more support for your opinions would greatly enhance your reviews... (\#114)

Gerame revised his reviews. The revision strategy, typical of that used by other students, was to add information to the final draft. For example, in describing the special effects in Youthink, Gerame's first version simple listed the effects:

- Animated Characters

- $\quad$ Lined Paper Background

- $\operatorname{Music}(?)$

Figure 1 presents Gerame's second draft.

\section{E-zine: Youthink \\ Target Audience: High School students}

\section{SECTIONS (for example, editorial, reviews, poetry...)}

I feel that Youthink was by far the best site I visited. The sections were intriguing, informative and provided a mouthful of goodness. Some sections include: Youthink, submit, contests, teachers, reviews, about us

\section{SPECIAL EFFECTS}

In the field of catchy diagrams, pictures and music, Youthink is severely lagging. It would be a much better site if the editors provided some eye-catching displays of computer knowledge. The site would greatly benefit by more graphics. Some features include.

$\$$ Animated Characters

$\$ \quad$ Lined Paper Background

\$ Music (?)

\section{DESCRIBE ONE ARTICLE OR SECTION}

Title: Arrogant Worms Rock the Ridge

Author: Donna Taylor - Garibaldi, Maple Ridge

Description: The article is a review on the Arrogant Worms' performance in Maple Ridge. The reviewer raves that the Arrogant Worms played some of their more popular songs, like "I am Cow" and "Jesus' Brother Bob." I enjoyed the article and definitely thought it was well written and interesting. I would enjoy more articles like this on other site.

Appeal to Teens: With its well written dialogue and its up to date reviews on the alternative music scene, any teenager who enjoys good music would love this site.

Rating: A

Figure 1. Gerame's review.

Gerame enjoyed chatting on the blog and posted most reviews and drafts there. He continually experimented with flash videos and included several attachments for students to 
view. Although the substance of the e-zines he reviewed did not appear to influence his contribution to the group section, his experiences as a camper complemented the interests of Ariel and Maddy. His awareness of the hypermedia features of e-zines and his expertise in design enabled him to design the central page and links in The Great Outdoors.

Ariel Ana Dew was a serious young woman. She was absent for several days at the beginning of the project and so did not respond to the first journal entry which had invited students to describe their technological skills. She was familiar with word processing, cutting and pasting, hypertext, and navigating links to different sections of the e-zines she reviewed.

Ariel enjoyed poetry and was drawn to Wet Ink Magazine where she read and interpreted a poem and a visual. In an early journal entry she commented on one poem she had discovered in Wet Ink Magazine:

The arts section had really good poetry in it. The poems are very descriptive and they have lots of feelingd in it. There was one poem that I didn't really understand, (its called "Draping Vision") but I still liked it because I axially like poems that have very descriptive words but I undferstand and I don't understand it at the same time - I don't know why, though. I like to read poetry on this the e-zines. (\#26)

She also commented on a painting she found in Wet Ink Magazine:

I like in particular part of the e-zine are the visuals on wet ink magazine and shows a picture of someone that is standing by an ocean. The title of the visual is called "Look ahead." The visual means that a person is standing by an ocean and thinking of the past. If we look in the future, the future won't look as bad after all. The ocean has all these sayings about the future of yourself. (\#26)

Ariel's contributions to the group section, The Great Outdoors, were influenced by the creative texts she had read in the e-zines as well as by her love of the outdoors. In a journal entry she wistfully explained that,

I'm glad that I came up with a creative arts section and taking picture's of the Sleeping Giant. I love the great outdoors of Thunder Bay! If my dad had more money and if my mom had a job, I would ask them if I could go camping during the summer. To be honest, I never went camping before. I would love to go camping some day if I would even have the chance to.

I was also suggesting of taking pictures of the Sleeping Giant around the Terry Fox monument. It is so beautiful when it is sunset. You could see different, vibrant colours above Sibley Park and the moon shining on the Lake Superior waters. That 
would be a beautiful picture of the Sleeping Giant. I hope you agree with this idea! (\#529)

Ariel contributed occasionally to the public blog area to report on the progress of her group and to post her writing. She did not participate in chats. She wrote regularly in the private journal and communicated orally with her group.

Maddy Black was an avid computer user. In his first journal entry he described his first impressions of e-zines as well as his "techie" skills:

My first impression of E-Zines was that I thought they were cool. They are a fun way to get information around on the web. They also are full of useful fact for almost any topic.

The first E-Zine I looked was Kid outdoors. This is a neat E-Zine all about the outdoors. It tells you when and where to go to have an enjoyable trip. It also shows you how to decide what and what not to bring. Another cool E-Zine is No Flying No Tights. This gives reviews about all different novels and comics stating which to read and which are just a waste of time depending on your interests.

The computer is a useful device. I often use it to type my school projects. I also use it to search for data. The computer is a fun way to play games on disks and online. I enjoy going on game sites to check out what kind of different activities there are. As well as this, I enjoy going on science sites and talking to my friends on MSN. It is also fun to play games on cd's.

I use the computer as well for writing music pieces on FINALE, a music program. I also enjoy creating fun clip-art on Macromedia Flash.

I have a few techie skills. I can take files from one program and transfer them to another. I am also skilled in many programs related to the computer desktop and the web. I can create a website and post it. I can also draw files from certain program and put them onto a website.

Sometimes I enjoy making copies of games and editing their programming which changes the way the game functions.

The only think I have trouble with is typing with my eyes on the screen. (\#28)

Maddy's contributions to the group project were influenced by his experience as a hiker and camper as well as by his review of a section of the e-zine, Kid Outdoors, on what to pack for a hike.

Negotiation and collaboration. Once the reviews had been completed, the teacher asked students to post a journal entry on their ideas for the e-zine. In her private journal, Ariel commented: 
To make the e-zines, I was maybe thinking of posting a variety of things on the ezines. (e.g. sports, poetry, artwork, music, bands, etc.) I think it would be a creative thing to because not everybody likes the same thing! What if a person doesn't want to read topics about sports?... I was also thinking of putting some poetry on the ezine. I think poetry would be a great thing, especially when some people need to have some comfort in their live, and some people need to read an in particular kind of poem to relieve themselves.

There should be some artwork on the e-zine (if my team members agree with it) in case anyone likes to look at a picture and go, "Man, I love this picture because..." or, like this picture because I like how it's so colourful and creative." (\#430)

Ariel stressed the importance of creativity through such genres as poetry and art. She also expressed concern about consensus and collaboration versus personal interest.

Once students had posted individual ideas on the e-zine, the teacher provided time for the groups to discuss the section they would contribute to the e-zine. Initial posts were vague and lacked detail. For example, Gerame posted the results of the initial group discussion:

Group Number 6 has proposed to submit a page combining the topics of "Poetry," the "Outdoors" and "Entertainment Reviews." The page will be structured in a way that resembles a magazine page, hopefully with Flash MX videos providing some creativity and appeal. (\#433)

Ariel expressed a concern for fairness in a follow-up posting:

We are doing three topics on "poetry," "outdoors," and "entertainment." We thought there should be a variety of subjects to make it fair for us, and have people who have a variety of topics. What do you think? (\#445)

The teacher encouraged the group to provide greater detail and to reach a consensus: "Focus on one idea and let it blossom" (\#476). Again, time was allotted for small group discussions. In his fourth journal entry, Gerame described the decision:

Today I think our group made good progress towards our topic and our article/section. Hopefully the outdoors section will go as planned, but I have a feeling our topic may be twisted a little before it gets onto the site. The outdoors was a great section to choose, since we are blessed with LOTS of material to write about here in Northwestern Ontario. I enjoy camping, and was assigned to do reports and give advice on local campsites, like Quetico and the Sleeping Giant National Park. (\#518) 
The teachers noted that most plans were too ambitious to complete within the timeframe. We cautioned students to consider what they might reasonably accomplish in the time available. Ariel reflected on the final decision reached by her group:

I want to do the poems and stories for the project of the e-zine. At first, I thought it wasn't fair that we should just choose one topic and we should choose a variety of topics instead. Today, now I agree with Mr. Paddington that we have to choose one main topic instead of three main topics. Now that I look back, I'm like "I can't believe that I wanted three main topics on the e-zine. It is too much now. I don't know why I wanted to have three main topics on one e-zine. (\#529)

Both Gerame and Maddy researched their topics. Gerame also searched the Internet for pictures of Thunder Bay. The group then decided that Maddy would take digital photos to add to the section.

One issue the teachers raised with the class was copyright. Students were cautioned to avoid plagiarizing content they found on the web. A number of blog entries vigorously discussed the issue. A related issue was that the students did not know how to cite and reference sources. One person from another group struggled with devising strategies to cite his sources. It would appear that this skill is taught in the secondary school curriculum when students begin to write formal reports.

In one journal entry Maddy described his engagement with the project and challenges he encountered while doing his research.

With the topic of the outdoors I have discovered a few interesting facts. Sleeping giant national park got its name at around 1988. Before this, it was called Sibley National Park. I also discovered many of the types of birds that live al over Ontario. As well I found out what brands of camping gear are good to buy and which are not so good.

The main challenge I encountered is doing the sections for reviews was trying to find free information on camping gear. You need to have an account to access most of the camping gear information. There were also a few other minor set backs like the file not saving or not being able to enter a sight.

Mostly for the section of the e-zine I am doing, the skills I use are reading and typing. I read the information on the web page then I type it into my own words.

This unit has been very fund and never gets boring. I am happy that we finally got to the first stage of creating the e-zines. I cannot wait until we see the finished copies. (\#618) 
Gerame commented on the progress of the group and the challenges he was experiencing in another journal entry. Each paragraph was printed with a different colour ink:

For our subject, we selected a section about the outdoors. It is very interesting so far, and I am learning things I did not know before about my favourite campsite: Sleeping Giant Provincial Park. Some basic things I didn't even know about before I started writing this (for example, the park used to be called "Sibley").

Maddy and Ariel are also doing the wilderness-themed topic, but on slightly different subjects. Maddy's writing reviews on camping gear like flashlights, sleeping gear and backpacks, and so far it looks very good. Ariel is writing stories and poetry on the outdoors, although I have not seen her finally copy yet. I think that our page will turn out really well.

My article is about my experiences in Sleeping Giant Provincial Park. It looks really good so far, in my opinion. I tried to put in links to other pages, but unfortunately I don't think it will go onto the web properly. I put in a picture of a nuthatch for the background by using a watermark, but unfortunately in stretched and became "DIGITALLY DISTORTED!" The rest of my article appears to be working fine, however... (\#628)

Once the group members had composed their drafts, the teachers assisted with revising and editing. Ariel took a long time to compose her draft. She decided to write a journal entry to create a mood of excitement about a family adventure to scenic spots in the Thunder Bay area. None of the group members made substantive revisions to the "print" texts. Each group member, however, demonstrated an awareness of writing in an electronic environment. Ariel experimented with background colours and layout for her piece. Maddy created a page to link to his review of camping gear which features links, an overview, and a digital photo of a teddy bear with a backpack. The page demonstrates his understanding of design and layout. Gerame wrote his review and created the main page for the section. The navigation buttons appear on brown rectangles with green print. The print changes to yellow when the links are clicked. He used different size fonts and included a digital photo of the Sleeping Giant.

Canteen: A site for Canadian Teens (http://flash.lakeheadu.ca/ teenezine) 
Role of the design team. As the six response groups were revising the proposals for their sections, the teacher initiated whole class discussions about the role of the design team. He posed three key questions:

- What should be the tasks of the design team?

- What qualities should people on the design team have?

- Who will be on the design team?

The class reached consensus on the tasks and qualities. These were posted on the blog:

Design Team Tasks

1. "Webmasters"

2. Title: Naming the site.

3. Structure of the site.

4. Presentation of links.

5. Communication between groups and entire class.

6. Meetings (daily)

7. Consensus (strive to obtain an overall agreement)

8. Information back to group members.

Design Team Qualities

1. Responsible

2. Understanding of project

3. Computer skills

4. Creativity

5. Cooperative/personable/able to be a team player

6. Communication skills (\#507)

The response groups decided on the following sections for the e-zine: movie reviews, drugs and alcohol, sports, game reviews, extreme sports, and the outdoors. Each group then nominated a representative to the design team. Three of the representatives who subsequently played leadership roles included Gerame (outdoors) Webmaster (movie reviews) and Bobathy 14 (extreme sports).

The design team met daily with a student teacher who was doing his field placement with the classroom teacher. At their first meeting Gerame suggested that the group focus on Thunder Bay as a theme. Bobathy 14 said that he knew a local professional photographer and would see whether he could obtain permission from her to use some of her photos of Thunder Bay in the e-zine. (Lori Fox Rossi's photo of the city at night is the 
focus of the main page.) Another student commented on how easy it would be to use Front Page as the software. Unfortunately, as we would subsequently discover, the school board did not have copyright permission to use this software. We then downloaded Dream Weaver which is covered by a licensing agreement by the Ontario Ministry of Education for use in schools and postsecondary institutions.

Only one student, Webmaster, was familiar with Dream Weaver software. He gave a demonstration lesson to the design team members. Gerame quickly transferred his skills to using the new software. He, Webmaster, and Bobathy 14, the three students with considerable technological expertise, demonstrated social learning (Leu, Jr. et al., 2004). They cheerfully responded to all requests for assistance by teachers and students.

Design team members discussed roles and assigned specific responsibilities to individuals. These responsibilities included: Webmasters; Editor of the front page and links to sections/layout; background, music and pictures; "supervisors" who would make sure that everyone was on task; and a flashmaster. It should be noted that many of the boys created outstanding flash videos, but had difficulty transferring them to the section files and, ultimately, to the website for the e-zine.

On one occasion Webmaster consulted the classroom teacher about how to upload photos to the website. The teacher recommended that any response group that had photos should incorporate them into section files. That same day the design team discussed the name of the e-zine and someone suggested Canteen (for Canada Teens). Everyone accepted the idea immediately. The team also discussed layout of the main page and the navigation links. The computer science teacher came in on two occasions to assist the class and to demonstrate to the design team how to create links to sections and how to link sections to the main page. The design team listened intently and contributed questions and comments during the mini lessons.

Successes and challenges. As noted above, only one student had had experience with Dream Weaver. Another challenge was that the firewall at the University blocked Language and Literacy

Volume 10 Issue 1 Spring 2008 
access to the server. This setback took three days to sort out and, by then, time allotted to the project had run out. All the sections had been compiled and Webmaster and Bobathy 14 were assigned the task of uploading the sections to the website. While much of the e-zine functioned smoothly, there were still some technical difficulties to correct. Following the completion of the e-zine project, the students, parents, and teachers celebrated with a class excursion to the University's advanced technology centre. Everyone toured the facility and then went to a computer lab where students proudly showed their parents the e-zine and later feasted on juice and cookies.

Reconstruction of the e-zine. The university researcher worked with an instructional designer to reconstruct the e-zine and correct the technical difficulties. Following the completion of the e-zine website, the researcher asked the instructional designer to analyze students' web design skills and identify computer and hypertext skills which students should learn in order to complete this type of project successfully. Figure 2 presents the analysis of website design skills (O'Brien, email 06/06/20).

Among the web design skills students demonstrated were the ability to conceptualize user-friendly navigation, including the use of icons and consistent design as visual aids for the user. Students would benefit from more guidance in understanding basic web design concepts and conventions and experience in using web design and graphics software.

\section{Discussion}

The findings in this study contribute to literacy researchers' understanding of the implementation of multiliteracies pedagogy in classrooms and research into young adolescents' engagement with and response to digital texts. The study has implications for educators and teacher educators as well as for literacy researchers in the conduct of literacy research, particularly in the use of the construct, transmediation (Eagleton, 2002; Leland \& Harste, 1994), to analyze and illuminate the language processes young adolescent use in the comprehension and construction of meanings. 
The unit provides a model for teachers (Eisner, 2002) for the implementation of multiliteracies pedagogy. The WebQuest was an effective approach for the implementation of the e-zine project. The format enabled teachers to pose an authentic task to challenge students and to create links to age- and content-appropriate e-zines. The WebQuest provided scaffolding for students to develop an understanding of the e-zine genre and conventions of the medium. Both the WebQuest and the creation of Canteen provided opportunities to link students' in-school and out-of-school literacies. Students were engaged in their learning and had ownership of the project. 


\section{Website Design Skills}

Analysis of the Teen E-Zine web site makes it apparent that the students possess many of the skills, talents and characteristics integral to successful web site design. These strengths include:

- Strong group concepts that, when combined, achieved a cohesive and effective overall site

- Creative approach to content presentation including animation, sound, graphics and use of colour

- Understanding of, and respect for, copyright issues

- Ability to conceptualize user-friendly navigation, including the use of icons and consistent design as visual aids for the user

- Willingness to work as a team, sharing resources and expertise

There are two main areas in which the students require more guidance:

1. Understanding of basic web design concepts/conventions, including:

- File management:

- proper file naming conventions (ie. lower case, no spaces)

- effective use of folders to organize files

- acceptable files sizes for multimedia and graphics

- HTML:

- basic html for troubleshooting

- differences in browser interpretation and display

2. Experience with effective software packages, which include:

- Web design software:

- designing browser compatible web pages

- converting non-html files to html

- Graphics software:

○ editing existing graphics

- creating original graphics (O'Brien, email, 06/06/20)

Figure 2. Analysis of website design skills. 
The students in the Grade 8 demonstrated social learning (Leu, Jr. et al., 2004). As well, the findings illuminate the processes through which individuals, response groups and the class constructed meanings. Students negotiated and collaborated to articulate themes, develop proposals for sections, research and create sections and design the main page. In this class, peers were comfortable taking risks, sharing ideas, and asking for assistance without fear of ridicule. Peers were complimentary about others' accomplishments and talents.

The role of the classroom teacher was critical to the success of the project. He created a positive and nurturing learning community, set high expectations for achievement and monitored students' interactions and behaviours continuously. His early intervention in the instance of a "putdown" prevented the possibility of the enactment of unequal power relations in the class and cyberbullying. He set the agenda each day and scaffolded students' learning through modelling, demonstration, whole class discussions, and teacherstudent conferences. He encouraged social learning by advising students to recognize each other's talents and to assist one another in accomplishing tasks. The teacher also invited the assistance of the computer science teacher who scaffolded students' learning of hypertext and computer literacy skills.

The study also provides insights into the students' identities and social practices. The selection of the particular themes they developed provides insights into their interests and concerns as well as elements of the popular culture they consider important. While the selection of themes for Canteen reflects interests and concerns shared by many teens across Canada, the individual sections and contributions illuminate some of the social practices in which students engaged outside of school. Gerame and Maddy, for example, were campers for whom camping is a social practice. Similarly, the authors of the game reviews were serious and sophisticated gamers. All of the students engaged in digital literacy as a social practice. 
The construct of transmediation (Eagleton, 2002; Leland \& Harste, 1994) provides a useful lens that illuminates the multiple sign systems through which students comprehended and expressed meaning. In the digital literacy project, students orchestrated multiple sign systems simultaneously. As did the students in Eagleton's (2002) webzine project, this class used oral language, print, visual literacy, computer and hypertext literacies. Eagleton found that in her study students used four hypermedia cueing systems: text, graphics, photography, and icons. Webmaster's section page on movie reviews illustrates how the cueing systems are integrated to create powerful visual images and information text. The construction of meaning involved the simultaneous and recursive orchestration of multiple sign systems.

The findings support Goldberg's (2001), Eagleton's (2002) and Marshall's (2000) contention that students need to have fluency in the conventions of a semiotic system in order to use that sign system to express meaning. In the study, the students demonstrated a number of skills in website design. They would have benefited had they had a greater understanding of conventions such as file management and html as well as more experience with web design and graphics software. One of the challenges we faced in this study was the need to use Dream Weaver in which everyone, except Webmaster, had to develop fluency.

With print literacy, students must learn how to conduct research, analyze and synthesize data, report findings in a variety of ways and acknowledge sources. Formal report writing is a curriculum expectation in the secondary school. However, even young children are required to do research projects. Teaching research and study skills continuously through elementary and secondary school might reduce plagiarism, particularly when the plethora of information available on the Internet lends itself so readily to cutting and pasting.

Several pedagogical implications are evident in this study. Firstly, it is critical that educators integrate students' in-school and out-of-school literacies in their literacy 
programs. For many of us, this involves tremendous risk-taking as we engage in new learning. Collaboration with colleagues would help to resolve this challenge. Further, if we promote social learning in our classrooms, we would be able to tap into the expertise that young people bring to school. Secondly, we need to consider multiliteracies from the perspective of students. A literacy program which incorporates multiliteracies has the potential to engage students more deeply in their own learning and provide instructional opportunities for teachers to provide guidance which enables students to develop "their understanding of and ability to successfully navigate this electronic landscape" (A.E. O'Brien, personal communication, 06/04/21). Thirdly, literacy instructors in teacher education programs must reflect on the assumptions and conceptualizations of literacy teaching that they present to teacher candidates. Traditionally, the emphasis has been placed on oral communication and print literacy. While print literacy continues to be a critical dimension of literacy courses, we must also consider ways to incorporate into these courses concepts and strategies related to media and multiliteracies. Many teacher candidates will have expertise in hypermedia and/or other sign systems although they may not recognize these as literacies. We need to encourage them to experiment with ways to engage with and respond to electronic and print texts, and to express meanings through the creation of texts which require orchestration and transmediation between and across sign systems. Bringing teacher candidates' in-school and out-of-school literacies into literacy courses would serve as a powerful model for them to (re)conceptualize literacy and to emulate in their future literacy practices.

The widespread use of the Internet and other digital technologies has contributed to researchers' understanding of the complex interactive multiliteracies which language users employ in simultaneous and recursive ways to comprehend and express meanings. It has also contributed to out-of-school social practices that differ from those in which teens engaged even a decade ago. At the same time, digital technologies have illuminated new constructs for analysis and interpretation. Transmediation (Leland \& Harste, 1994; Eagleton, Language and Literacy

Volume 10 Issue 1 Spring 2008 
2002) provides a powerful construct for interpreting teens' processes of engagement and response in ways that more fully represent the complexity of literacy and the language processes. The use of this construct may provide literacy researchers a methodological tool for data analysis and interpretation.

\section{Acknowledgements}

1. The authors would like to thank Lori Fox Rossi, professional photographer, for permission to use her beautiful photo of Thunder Bay at night on the main page of Canteen. (www.lorifoxrossi.com)

2. The authors would also like to thank Anne Elizabeth O'Brien, instructional designer, for her reconstruction of the website and the analysis of the students' web design skills (www.aeobrien@tbaytel.net)

\section{References}

Bogdan, R.C., \& Biklen, S.K. (2003). Qualitative research in education: An introduction in theory and methods ( $4^{\text {th }}$ ed.). Boston, MA: Allyn \& Bacon.

Courtland, M.C., Leslie, L., Karpiuk, P., \& Petrone, J. (forthcoming). Exploring issues in humane and environmental education through drama. English Quarterly.

Courtland, M.C., Niemi, S., Paddington, D., \& Magnusson, R. (2006). Burning gender: Artistic responses to Ellis' The Breadwinner (2000) in a Grade 8 classroom. Language and Literacy: A Canadian E-journal, 8(1). Retrieved from:

http://www.langandlit.ualberta.ca/current.html

Courtland, M.C., \& Gambell, T.J. (Contributing Eds.). (2000). Young adolescents meet literature: Intersections for learning. Vancouver, BC: Pacific Educational Press.

Eagleton, M. B. (2002, July/August). Making text come to life on the computer: Toward an understanding of hypermedia literacy. Reading Online, 6(1). Available: http://www.readingonline.org/articles/art_index.asp?HREF=articles/eagleton2/index. html 
Eisner, E.W. (2002). The educational imagination: On the design and evaluation of school programs. ( $3^{\text {rd }}$ edition). Upper Saddle River, NJ: Pearson Education.

Goldberg, M. (2001). Arts and learning: An integrated approach to teaching and learning in multicultural and multilingual settings ( $2^{\text {nd }}$ ed.). New York: Longman.

Kist, W. (2005). New literacies in action: Teaching and learning in multiple media. New York: Teachers College Press.

Leland, C. H., \& Harste, J. C. (1994). Multiple ways of knowing: Curriculum in a new key. Language Arts, 71, 331-345.

Leu, D. J., Jr., Kintzer, C. K., Coiro, J., \& Cammack, D. W. (2004). Toward a theory of new literacies emerging from the Internet and other information and communication technologies. In R. B. Ruddell \& N. Unrau (Eds.), Theoretical models and processes of reading ( $5^{\text {th }}$ ed.) (pp. 1570-1613). Newark, DE: International Reading Association. Available: http://www.readingonline.org/newliteracies/lit_index.asp?HREF=leu/

Mashall, J. (2000). Research in response to literature. In M.L. Kamil, P.B. Mosenthall, P.D. Pearson, \& R. Barr (Eds.), Handbook of Reading Research, Volume III (pp. 381-402). Mahwah, NJ: Lawrence Erlbaum.

Pahl, K., \& Rowsell, J. (2005). Literacy and education: Understanding the New Literacy Studies in the classroom. London: Chapman; Thousand Oaks, Ca: Sage. Patton, M.Q. (2002). Qualitative research and evaluation and research methods ( $3^{\text {rd }}$ ed.). Beverly Hills, CA: Sage.

Smagorinsky, P. (2002). Teaching English through principled practice. Upper Saddle River, NJ: Pearson Education.

\section{Information on WebQuests}

www.webquest.org 